原著

Nd: YAGレーザーの表面麻酔効果

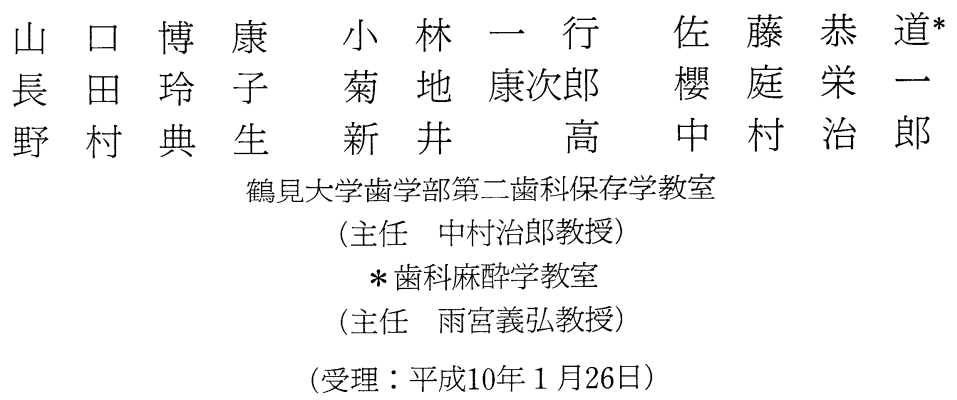

\title{
Surface Anesthesic Effect of Nd:YAG Laser
}

\author{
Hiroyasu YAMAGUCHI, Kazuyuki KOBAYASHI, Yasumichi SATO*, \\ Reiko OSADA, Kohjiro KIKUCHI, Eiichi SAKURABA, Tsuneo NOMURA, \\ Takashi ARAI and Jiro NAKAMURA \\ Department of Periodontics and Endodontics, Tsurumi University School of Dental Medicine \\ (Chief:Prof. Jiro NAKAMURA) \\ * Department of Dental Anesthesiology \\ (Chief: Prof. Yoshihiro AMEMIYA)
}

(Accepted for Publication: January 26, 1998)

\begin{abstract}
This study was performed in order to evaluate the irradiative effect of Nd:YAG laser on surface anesthesia. Eleven students at Tsurumi University School of Dental Medicine participated in this study as subjects. Experimental sites were gingivobuccal areas of mandibular canines. The right area was irradiation site, and the left area was control site without irradiation. A pulsed Nd:YAG laser was applied to the areas coated with indian ink, twice for 30 seconds, using $120 \mathrm{~mJ}$ pulses at $10 \mathrm{pps}$. The judgement of the effect was made through the measurement of the penetrating distance of $30 \mathrm{G}$ catridge needle,and the measurement was performed immediately after the irradiation and after a week. The efficasy of pain was assessed by Visual Analogue Scale (VAS). The mean penetrating distance of needle at the irradiation sites revealed $3.8 \pm 1.4 \mathrm{~mm}($ Mean $\pm \mathrm{SD})$ at immediately after the irradiation compared to the control sites $1.7 \pm$ $0.9 \mathrm{~mm}$, and in 6 cases needle was inserted into periosteum without pain. There was a significant difference $(\mathrm{p}<0.01)$ between the irradiation sites and the control sites. The VAS value revealed $2.7 \pm 2.9$ at the irradiation sites, and $4.2 \pm 2.6$ at the control sites. The penetrating distance of needle at the irradiation site after a week revealed $0.6 \pm 0.4 \mathrm{~mm}$, and at the control sites of $1.6 \pm 1.0 \mathrm{~mm}$. The anesthetic effect of the irradiation of Nd: YAG laser was lost after a week. It was suggested that the irradiation of Nd:YAG laser has anesthesic effect on gingival surface, and
\end{abstract}

テ230-8501 神奈川県横浜市鶴見区鶴見2-1-3 TEL 045-581-1001 FAX 045-573-9599

2-1-3, Tsurumi, Tsurumi-ku, Yokohama 230-8501, Japan. TEL 045-581-1001 FAX 045-573-9599 
that the effect will disappear within 1 week.

(J. Jpn. Soc. Laser Dent. $9:$ 9 12, 1998 Reprint requests to Dr. YAMAGUCHI)

\section{Key words=Nd: YAG Laser : Surface anesthesic effect.}

\section{キーワード=Nd: YAGレーザー:表面麻酔効果}

\section{緒言}

歯科臨床において疼痛を与えず治療を行うことは，患 者の心身の負担を軽減し能率的な治療を進める上で重要

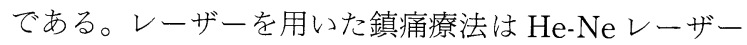

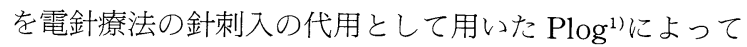
1973年初めて報告された。我国では低出力レーザーを頭 痛などのペインクリニックに応用しており ${ }^{2,3)}$, 歯科領域 では知覚過敏に対する効果 ${ }^{4)}$ や麻酔効果 ${ }^{5 \sim 7}$ について報 告されてきた。

当教室では高出力レーザーの象牙質に対する作用, LPS(Lipopolisaccharide) に対する作用など，In vitro において研究を行い, Er: YAGに比較してNd: YAG レーザーは熱による効果が主であることを明らかにして

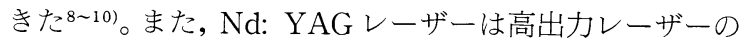
なかでも最も多く臨床に扔いて利用され, Nd: YAGレ ーザー照射により歯䯣疼痛閾值を高めることによって麻 酔効果が得られるという報告がされている5 てでこで本 研究ではレーザーによる表面麻酔の臨床的効果を明らか にする目的で, 歯肉頛移行部歯槽粘膜に Nd: YAGレー ザーを照射し歯肉表面の疼痛緩和 (以後, 表面麻酔効果) の研究を行った。

\section{材料と方法}

健全な歯周組織を有する鶴見大学歯学部学生11名（男 性 8 名, 女性 3 名, 平均年齢24.5歳) を被験者とし, 健全 下顎左右犬歯歯肉煩移行部を被験部位に用いた。右側を 照射側, 左側をコントロール側とし, 照射部位にはIndian inkを塗布後, Nd: YAGレーザー (American Dental Technologies Pulse Master 600)を $120 \mathrm{~mJ}, 10$ pps，30秒間の条件で 2 回照射した（図 1 ）。

照射後根管治療用ラバーストッパーを取り付けた $30 \mathrm{G}$ 注射針（テルモ，東京）（図 2)を，歯肉煩移行部に被験 者が痛みを感じるまで刺入した。表面麻酔効果は刺入距 離をノギスで測定し判定した。なお痛みを感じないで骨 膜まで達した場合はその深さを刺入距離としてノギスで 測定した。効果の判定は照射直後, 1 週間後に行った。 また相対的な痛みの指標はVisual Analogue Scale (VAS)を用いて調べた。得られたデー夕を paired-t 検定
により統計学的に検索した。

\section{結果}

照射直後の注射針刺入距離はコントロール側では $1.7 \pm 0.9 \mathrm{~mm}$ (Mean $\pm \mathrm{SD})$ であったのに対し照射側では $3.8 \pm 1.4 \mathrm{~mm}$ と有意差 $(\mathrm{p}<0.01)$ が認められた（表 1 )。また骨膜まで達した被験者は11名中 6 名（男性 5 名, 女性 1 名）であった。VAS 值は照射側で2.7 2.9 , コントロール側で $4.2 \pm 2.6$ と照射側でやや低值を示した が有意差は認められなかった（表 2 )。

1 週間後の刺入距離は照射側で $0.6 \pm 0.4 \mathrm{~mm}$ であり, コントロール側で $1.6 \pm 1.0 て ゙$ 有意差は認められなかった。

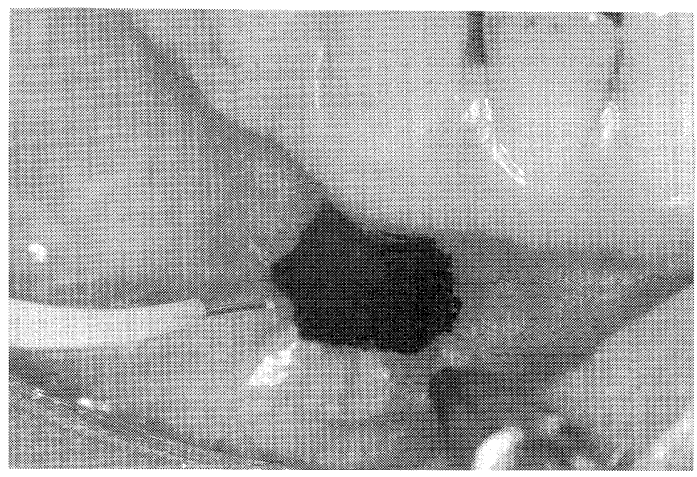

図 1 レーザー照射方法

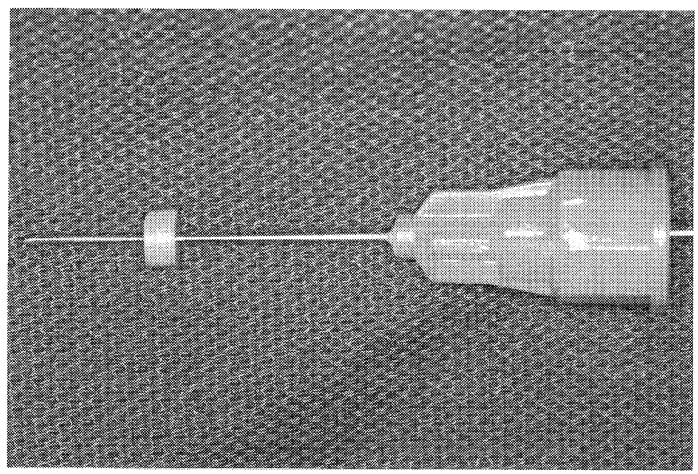

図 2 ラバーストッパーを付与した $30 \mathrm{G}$ 注射針 
表 1 表面麻酔の評価

\begin{tabular}{l|cc}
\hline \multicolumn{3}{|c}{ 注射針刺入距離 } \\
\hline & 照射直後 & \multicolumn{1}{c}{ 1 週間後 } \\
\hline & \multicolumn{2}{|c}{$*$} \\
照射側 & \multicolumn{2}{|c}{} \\
コントロール & $*$ [ $\begin{array}{r}3.8 \pm 1.4 \mathrm{~mm} \\
1.7 \pm 0.9 \mathrm{~mm}\end{array}$ & $0.6 \pm 0.4 \mathrm{~mm}$ \\
& & $1.6 \pm 1.0 \mathrm{~mm}$ \\
\hline
\end{tabular}

$\left({ }^{*} \mathrm{p}<0.01\right) \quad$ Paired $t$-test

Mean \pm SD $(n=11)$

表 2 痛みの評価：Visual Analogue Scale（VAS）値

\begin{tabular}{l|ll}
\hline & 照射直後 & 1 週間後 \\
\hline & & \\
照射側 & $2.7 \pm 2.9$ & $2.6 \pm 1.7$ \\
コントロール & $4.2 \pm 2.6$ & $4.0 \pm 2.2$ \\
\hline
\end{tabular}

Mean \pm SD $(n=11)$

\section{考察}

現在までに神経組織に対する半導体レーザーの照射効 果の検索が行われており, Tsuchiya ら ${ }^{11)}$ はラット伏在神 経の $\mathrm{A} \delta, \mathrm{C}$ 線維の活動が抑制されると報告している。さ らに河谷ら ${ }^{12)}$ は半導体レーザーを大きなエネルギーの条 件1.8-9J で照射することにより知覚線維の中でも痛覚 の特に C 線維を特異的に抑制することを報告している。 目澤ら ${ }^{13}$ は低出カレーザーをネコ舌神経に照射し, 痛覚 に関与する線維の興奮抑制を明らかにしている。

生理学的に痛覚を伝える求心性線維として, 鋭痛また は速い痛みを伝えるのは有髄線維である A 痛または遅い痛みを伝えるのは無髄線維である C 線維 と考えられている。

口腔粘膜の中でも歯肉煩移行部に痛覚の神経線維の分 布が多いことが報告 ${ }^{14)} れ$, 本研究では特に痛覚に対す る影響を知るために被験部位に用い, また痛覚過敏 (hyperalgesia)を避けるために刺入点は 1 点とした。

被験者はレーザー照射側においての痛みの発現状態に ついて，注射針を刺入するに従い最初は痛みであるかよ くわからず，急に鈍痛が生じると感じる被験者が最も多 かった。それに対してコントロール側では注射針の刺入 とともに鋭い痛みを訴えていた。このことから $\mathrm{Nd}: \mathrm{YAG}$ レーザーは痛賞の中でも特に有髄線維である $\mathrm{A} \delta$ 線維に 効果を及汸し表面麻酔効果が得られたのではないかと考
えられる。また無髄線維であるC 線維に対しては十分な 効果が得られなかったと推察される。河谷ら ${ }^{12}$ 怯半導体 レーザーの出力を上昇させた場合, $\mathrm{A} \delta$, 特に C 線維に対 して闇値の上昇することを報告しているが本研究の結果 と一部類似している。C 線維に対して完全に効果が得ら れていないのは, 半導体レーザーと高出カレーザーの作 用機序が異なるためなのか, あるいは照射条件が熼なる ためなのか, 現在検索中である。

$\mathrm{Nd}$ : YAG レーザーは黒色に対して特異的に反応する

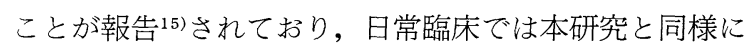
Indian ink 塗布し照射している20)。本研究に扔いても Indian ink 塗布しレーザーを照射したためレーザーの 効果は菌槽粘膜の表層に対する影響と考えられる。しか し塗布された黒色部位は照射により蒸散するが, 更に深 層についての影響は明らかではなく, 照射条件, Indian ink 塗布をずるか否かで変化すると考えられ以後この 点についても検討する予定である。

現在までに Nd:YAGレーザーを用い, 歯髄に対して 閾值を上昇させ, 麻酔効果, 疼痛緩和の得られた報告5,7,20) があり, 本研究においても, これらの照射条件より低値 に設定した。また, 当教室に抢汀る, 知覚過敏に対する Nd: YAGレーザー照射の疼痛緩和処置の研究20)では歯 肉煩移行部に $100 \mathrm{~mJ}, 15 \mathrm{pps}, 1.5 \mathrm{~W}, 60 \mathrm{sec}$ の条件で照射し, 照射部位の状態について術前, 術後に印象採得しレーザ 一顕微鏡を用いて観察したところ, 柬肉表面の影響はほ とんど認められなかった。

日常歯科臨床において浸潤麻酔を行う場合, 注射針刺 入及び麻酔剤注入に伴う疼痛は避け難く患者の苦痛とな る。しかし表面麻酔を用いることにより, 浸潤麻酔を無 痛的に行うことはある程度可能である。近年臨床応用さ れた貼付型表面麻酔剤16)やイオントフォレーシスの導 入 ${ }^{17)}$ は粘膜下約 $4 \mathrm{~mm}$ 前後, 骨膜周囲にまで麻酔効果が 得られる。しかし表面麻酔薬は唾液により希釈される欠 点がある。それに伴い麻酔薬が口腔内に流出し苦味を感 じてしまう。特にスプレーによる表面麻酔では気化熱に よる冷反応として一過性の疼痛を感じる18)。さらに効果 発現までには表面麻酔で 2 分以上，イオントフォレーシ スで十数分と時間がかかる16,18)。しかし Nd:YAGレーザ 一の表面麻醉は術式も比較的容易であり，短時間で効果 が得られることも利点と考えられる。

今後レーザー照射による歯髄への影響5 7), 疼痛緩和の 経時的変化, 温熱, 压年による影響などについても検討を 加え神経線維への影響, 半導体レーザーとの作用機序の 違いについても検索する必要がある。

\section{結 論}

Nd: YAGレーザーを下顎犬歯歯肉頓移行部に照射し 
た直後, 注射針の刺入が無痛的に可能となった。このこ とから Nd: YAGレーザーには表面麻酔効果のあるこ とが示唆された。

\section{謝 辞}

本実験に際し御協力頂きました株式会社デニックスに 感謝申し上げます。

本論文の要旨は第 9 回日本レーザー歯学会（1997年11月 1 日,大 阪）において発表した。

\section{文献}

1) Plog, F, M.W : Biophysical application of the laser beam. Lasers in Medicine.In:Koebner,H.K.ed.ChichesterNewYork Brisbane, Tronto,1980 John Wily and Sons 21 -37 .

2) 大西俊輝, 神川喜代男 : Laser acupuncture system の開発. 第 3 回医用レーザー研究会論文集，61-64 (1977).

3) 岡田武史, 大城俊夫, 加藤好雄, 柴崎昌浩：Gallium aluminium arsenide 半導体レーザーのペインクリニックへの応用, 麻酔 32 (2) : 246-252, 1983.

4）松本光吉, 船井博雄, 白須賀哲也, 若林始：Nd: YAG-Laserに よる歯頸部象牙質知覚過敏症の除痛効果について.日歯保存誌 $28: 760-765,1985$.

5) Whitters,C.J., Hall,A.,Creanor,S.L., Moseley, H.,Gilmour, W.H., Strang,R., Saunders,W,P., Orchardson,.R: A clinical study of pulsed Nd:YAG laser induced pulpal analgesia: J Dent 23,145-150,1995.

6) Parkins, F.,Miller, R : Nd:YAG Laser analgesia of dentin : J Dent Res 71,162 (abstr 450), 1992.

7) 内藤徹, 秋吉栄太郎, 横田誠: 局所麻酔剂アレルギーが疑われる 症例に対する Nd: YAGレーザー照射の応用：日歯保存誌, 40: (3) 793-799, 1997.

8）山口博康, 小林一行, 小澤寿子, 新井 高, 中村治郎: 高出力レー ザー照射による歯根象牙質への影響. 日歯保存誌，39：11291135, 1996.
9) 山口博康, 小林一行, 野村典生, 新井 高, 中村治郎:高出力レ ーザー照射によるLPSの構造変化. 日本レーザー歯学会誌, $8: 16-22,1997$

10) Yamaguchi, H., Kobayashi, K., Osada, R.,Sakuraba, E., Nomura, T., Arai, T., Nakamura, J.: Effects of irradiation of an Erbium:YAG laser on root surfaces. J.Periodontol., 68 : 1551-1555, 1997.

11) Tsuchiya, K.,Kawatani, M.,Takeshige, C.,Sato, T.,Matsumoto, I : Diode laser irradiation selectively diminishes slow component of axonal volleys to dorsal roots from the saphenous nerve in the rat: Neroscience Letters, $161: 65-68.1993$.

12）河谷正仁, 土屋喜由：低出力レーザーによる末梢感覚神経伝導 の遮断：ペインクリニック , 16:533-539.1995.

13）目澤修二, 塩野 真, 服部夏雄, 斎藤 毅, 内藤公郷, 岩田幸一, 鴨 川鉱征, 角野隆二：ネコ舌への電気および侵害的熱刺激に応答 する舌神経活動に対する舌表面への低出力レーザー照射効果. 日歯保存誌, $31: 584-593,1988$.

14）山田 守：口腔領域に扔ける痛みの生理, 歯界展望, $31: 1207-$ 1214,1968 .

15）森岡俊夫, 鈴木和男, 田篭祥子:Nd: YAGレーザー照射による エナメル質耐酸性増強に及ぼす歯面黒色塗布剤の効果について。 口腔衛生学会誌, 34：40-44,1984.

16）三浦一恵, 別部智司, 佐藤恭道, 関田俊介, 雨宮義弘：貼付型表面 麻酔剤 (ペンレス) の口腔粘膜麻酔効果に関する研究. 日歯麻誌 25(2) : 174-177,1997.

17）柬理十三雄, 藤井一雄, 鈴木友一, 吉川隆淑, 佐野公人, 北野智丸, 渡部圭吾, 郡山廣志, 高野和弘, 杉山尚隆. 歯科局所麻酔における iontophoresis の応用-第 1 報：ヒト歯肉および歯髄に対する 効果 日歯麻誌，18(4)：660-664,1990.

18）西野瑞穂：日歯庇誌 $18(4)$ 貼付型表面麻配剤の活用：日本歯 科評論, $529: 48-52.1986$.

19）中村治郎, 木下四郎, 中島善仁, 木村良一：20\%アネステジン塗 布麻酔薬の臨床応用：歯界展望, 16：(9) 108-111,1959.

20）小林一行, 山口博康, 熊井麻子, 田中麻起, 櫻庭栄一, 野村典 生, 中村治郎, 新井高：歯周治療中に生じた象牙質知覚過敏症 に対するレーザー照射, 日歯周誌，39：秋期特別号91,1997. 